\title{
Nuclear factor of activated T cells 4 in the prefrontal cortex is required for prophylactic actions of $(R)$-ketamine
}

\author{
Li Ma ${ }^{1,2}$, Jiancheng Zhang ${ }^{1,4}$, Yuko Fujita ${ }^{1}$, Youge $\mathrm{Qu}^{1}$, Jiajing Shan ${ }^{1}$, Xiayun Wan ${ }^{1}$, Xingming Wang ${ }^{1}$, Tamaki Ishima ${ }^{1}, \mathrm{Kenta} \mathrm{Kobayashi}^{3}$,
} Long Wang ${ }^{2}$ and Kenji Hashimoto (iD ${ }^{1 凶}$

(c) The Author(s) 2022

$(R, S)$-ketamine has prophylactic antidepressant-like effects in rodents; however, the precise molecular mechanisms underlying its action remain unknown. Using RNA-sequencing analysis, we searched novel molecular target(s) that contribute to the prophylactic effects of $(R)$-ketamine, a more potent enantiomer of $(R, S)$-ketamine. Pretreatment with $(R)$-ketamine $(10 \mathrm{mg} / \mathrm{kg}, 6 \mathrm{days}$ before) significantly ameliorated body weight loss, splenomegaly, and increased immobility time of forced swimming test in lipopolysaccharide (LPS: $1.0 \mathrm{mg} / \mathrm{kg}$ )-treated mice. RNA-sequencing analysis of prefrontal cortex (PFC) and subsequent IPA (Ingenuity Pathway Analysis) revealed that the nuclear factor of activated T cells 4 (NFATc4) signaling might contribute to sustained prophylactic effects of $(R)$-ketamine. Quantitative RT-PCR confirmed that $(R)$-ketamine significantly attenuated the increased gene expression of NFATc4 signaling (Nfatc4, Cd4, Cd79b, H2-ab1, H2-aa) in the PFC of LPS-treated mice. Furthermore, pretreatment with NFAT inhibitors (i.e., NFAT inhibitor and cyclosporin A) showed prophylactic effects in the LPS-treated mice. Similar to $(R)$-ketamine, gene knockdown of Nfatc4 gene by bilateral injection of adeno-associated virus (AAV) into the mPFC could elicit prophylactic effects in the LPS-treated mice. In conclusion, our data implicate a novel NFATc4 signaling pathway in the PFC underlying the prophylactic effects of $(R)$-ketamine for inflammation-related depression.

Translational Psychiatry (2022)12:27; https://doi.org/10.1038/s41398-022-01803-6

\section{INTRODUCTION}

Robust antidepressant action of the $\mathrm{N}$-methyl-D-aspartate receptor (NMDAR) antagonist $(R, S)$-ketamine is a paradigm shift for depression research and treatment [1]. In 2000, Berman et al. [2] demonstrated the rapid-onset and sustained antidepressant actions of $(R, S)$-ketamine in patients with major depressive disorder (MDD). Subsequently, several groups replicated the robust antidepressant effects of $(R, S)$-ketamine in treatmentresistant patients with MDD or bipolar disorder (BD) [3-10]. Metaanalyses revealed that $(R, S)$-ketamine has rapid-acting and sustained antidepressant effects in treatment-resistant patients with MDD or $\mathrm{BD}$ [11-13]. Although $(R, S)$-ketamine can produce the robust antidepressant actions in severe patients with depression, precise molecular mechanisms underlying its antidepressants remain elusive [14-22].

Dr. Denny and her colleagues demonstrated that $(R, S)$-ketamine could produce persistent prophylactic effects against chronic social defeat stress (CSDS) model, learned helplessness (LH) model, chronic corticosterone-treated model [23], and lipopolysaccharide (LPS)-treated inflammation model [24]. Furthermore, the same group reported prophylactic effects of $(R, S)$-ketamine against fear expression $[25,26]$. It is also reported that $\triangle$ FosB in the ventral CA3 of hippocampus plays a role in the prophylactic effects of $(R, S)$-ketamine in CSDS model [27]. Moreover, it is demonstrated that $(R, S)$-ketamine produced a robust pro-resilient response to CSDS through Akt signaling in the ventral tegmental area (VTA)-nucleus accumbens (NAc) [28]. Interestingly, Ma et al. [29] reported prophylactic effects of $(R, S)$-ketamine on postpartum depression in Chinese women undergoing cesarean section. Collectively, it is possible that $(R, S)$-ketamine may be useful in protecting against stress-related psychiatric disorders such as depression and posttraumatic stress disorder (PTSD) [30]. However, the precise molecular and cellular mechanisms underlying prophylactic actions of $(R, S)$-ketamine remain unclear.

$(R, S)$-ketamine $(\mathrm{Ki}=0.53 \mu \mathrm{M}$ for NMDAR) is a racemic mixture that contains equal amounts of $(R)$-ketamine (or arketamine) $(\mathrm{Ki}=$ $1.4 \mu \mathrm{M}$ for NMDAR) and (S)-ketamine (or esketamine) $(\mathrm{Ki}=0.30 \mu \mathrm{M}$ for NMDAR). In 2019, (S)-ketamine nasal spray for treatmentresistant MDD patients was approved in the United State and Europe. In contrast, increasing preclinical data show that $(R)$ ketamine displays greater potency and longer-lasting antidepressant effects than (S)-ketamine in rodent models of depression [31-41], suggesting that NMDAR does not play a major role in the robust antidepressant-like effects of $(R, S)$-ketamine. Importantly, side effects of $(R)$-ketamine are less than those of $(R, S)$-ketamine or (S)-ketamine [32, 38, 42-46]. A recent pilot study demonstrated that $(R)$-ketamine elicited rapid-acting and sustained antidepressant actions in treatment-resistant MDD patients, and that side

\footnotetext{
'Division of Clinical Neuroscience, Chiba University Center for Forensic Mental Health, Chiba 260-8670, Japan. ${ }^{2}$ Department of Anesthesiology, Renmin Hospital of Wuhan University, Wuhan 430060 Hubei Province, China. ${ }^{3}$ Section of Viral Vector Development, Center for Genetic Analysis of Behavior, National Institute for Physiological Sciences, Okazaki, Aichi 444-8585, Japan. ${ }^{4}$ Present address: Department of Critical Care Medicine, Union Hospital, Tongji Medical College, Huazhong University of Science and Technology, Wuhan 430022, China. ${ }^{凶}$ email: hashimoto@faculty.chiba-u.jp
}

Received: 28 October 2021 Revised: 4 January 2022 Accepted: 12 January 2022

Published online: 21 January 2022 
effects such as dissociation were very low [47]. Taken all together, it is likely that $(R)$-ketamine would be a novel antidepressant without side effects of $(R, S)$-ketamine [16-20, 22]. Meanwhile, there are no articles reporting the prophylactic effects of $(R)$ ketamine in rodents. Little is known about the precise molecular mechanisms underlying the prophylactic effects of $(R)$-ketamine.

The aim of this study was to identify the novel molecular mechanisms underlying the prophylactic effects of $(R)$-ketamine in LPS-induced inflammation model. First, we conducted RNAsequencing analysis of the prefrontal cortex (PFC) of LPS-treated mice treated with either $(R)$-ketamine or $0.9 \%$ saline, as PFC contributes to the antidepressant-like actions of ketamine and its enantiomers $[32,48,49]$. Furthermore, we examined the prophylactic effects of $(R)$-ketamine on LPS-induced splenomegaly in mice since LPS increased spleen weight through systemic inflammation [50]. Second, we studied the effects of pharmacological inhibitors and adeno-associated virus (AAV) vector of the novel target in the prophylactic effects of $(R)$-ketamine in LPStreated mice.

\section{METHODS AND MATERIALS \\ Animals}

Male adult C57BL/6 mice (8 weeks old, body weight $20-25 \mathrm{~g}$ ) were purchased from Japan SLC, Inc. (Hamamatsu, Shizuoka, Japan). Animals were housed under controlled temperature and $12 \mathrm{~h}$ light/dark cycles (lights on between 07:00-19:00), with ad libitum food and water. The study was approved by the Chiba University Institutional Animal Care and Use Committee (1-374, 2-146, and 3-282). All efforts were made to minimize suffering. The sample size was chosen as reported previously.

\section{Compounds and treatment}

$(R)$-ketamine hydrochloride was prepared by recrystallization of $(R, S)$ ketamine (Ketalar, ketamine hydrochloride, Daiichi Sankyo Pharmaceutical Ltd., Tokyo, Japan) and D-(-)-tartaric acid, as reported previously [31]. $(R)$-norketamine hydrochloride was synthesized as reported previously [33]. $(2 R, 6 R)$-hydroxynorketamine (HNK) hydrochloride was purchased from Tocris Bioscience (Tokyo, Japan). The dose $(10 \mathrm{mg} / \mathrm{kg}$ as hydrochloride salt) of $(R)$-ketamine, $(R)$-norketamine, and $(2 R, 6 R)$-HNK were selected as reported previously [32, 35-37, 51]. LPS (L-4130, serotype 0111:B4, Sigma-Aldrich, St Louis, MO, USA) was dissolved in saline. The dose $(1.0 \mathrm{mg} / \mathrm{kg})$ of LPS was used as reported previously [24]. The NFAT inhibitor (L-methionyl-L-alanylglycyl-L-prolyl-L-histidyl-L-prolyl-L-valyl-Lisoleucyl-L-valyl-L-isoleucyl-L-threonylglycyl-L-prolyl-L-histidyl-L-a-glutamyl-L-glutamic acid, Cat No.: 249537-73-3, Cayman Chemical, Ann Arbor, Michigan, USA) or cyclosporin A (CysA; Cat No.: 59865-13-3, FUJIFILM, Tokyo, Japan) was dissolved in 10\% dimethylsulfoxide (DMSO). The dose $(40 \mathrm{mg} / \mathrm{kg})$ of CysA was used as reported previously [52]. ANA-12 $(0.5 \mathrm{mg} / \mathrm{kg}$; Maybridge, Cornwall, UK), was dissolved in phosphatebuffered saline (PBS) containing 17\% DMSO and administrated intraperitoneally (i.p.) to mice $30 \mathrm{~min}$ prior to the administration of saline or $(R)$-ketamine, as reported previously $[32,53-57]$.

\section{LPS-induced depression model, and behavioral tests}

The mice were randomly divided into the groups. The procedure of LPStreated inflammation model for depression was performed as reported previously $[35,50,57,58]$. Locomotion test and forced swimming test (FST) were performed 23 and $24 \mathrm{~h}$ after i.p. administration of saline $(10 \mathrm{ml} / \mathrm{kg})$ or LPS $(1.0 \mathrm{mg} / \mathrm{kg})$, respectively. Behavioral tests were performed in a blind manner. Detailed methods were shown in the supplemental information.

\section{Collection of blood and spleen}

The mice were deeply anesthetized with inhaled isoflurane (5\%) $24 \mathrm{~h}$ after the i.p. injection of saline $(10 \mathrm{ml} / \mathrm{kg})$ or LPS $(1.0 \mathrm{mg} / \mathrm{kg})$. Blood was collected via cardiac puncture, placed into tubes containing ethylenediaminetetraacetic acid (EDTA), and immediately centrifuged at $3000 \times g$ for $3 \mathrm{~min}$ at $4{ }^{\circ} \mathrm{C}$ to obtain plasma, and then stored at $-80^{\circ} \mathrm{C}$ until bioanalysis, as reported previously [50]. Prefrontal cortex (PFC) was collected rapidly and stored at $-80^{\circ} \mathrm{C}$ until bioanalysis. The weight of spleens was recorded immediately after spleen removal.

\section{Measurement of pro-inflammatory cytokines in the blood}

The plasma levels of interleukin- 6 (IL-6) and tumor necrosis factor- $a$ (TNF-a) were determined using ELISA kits (IL-6: cat number: 88-7064, TNF-a: cat number: 88-7324, Invitrogen, Camarillo, CA, USA) according to the manufacturer's instructions.

\section{RNA-sequencing analysis}

$(R)$-ketamine $(10 \mathrm{mg} / \mathrm{kg})$ or saline $(10 \mathrm{ml} / \mathrm{kg})$ was administered i.p. to mice 6 days before i.p. administration of saline $(10 \mathrm{ml} / \mathrm{kg}$, i.p.) or LPS $(1.0 \mathrm{mg} / \mathrm{kg}$, i.p.) (Fig. 1A). PFC was collected $24 \mathrm{~h}$ after a single administration of saline or LPS. RNA-sequencing analysis of the PFC samples was performed the Novogene (Beijing, China). Analysis of the biological functions was performed using the Ingenuity pathway Analysis (IPA) [59].

\section{Quantitative real-time PCR}

Saline $(10 \mathrm{ml} / \mathrm{kg})$ or $(R)$-ketamine $(10 \mathrm{mg} / \mathrm{kg})$ was administered i.p. to mice 6 days before LPS ( $1.0 \mathrm{mg} / \mathrm{kg}$, i.p.) administration. Mice were sacrificed $24 \mathrm{~h}$ after administration of saline or LPS. Mice were sacrificed under deep anesthesia by isoflurane (5\%), then PFC was quickly dissected on ice from the whole brain.

A quantitative RT-PCR system (Step One Plus, Thermo Fisher Scientific, Yokohama, Japan) was used. All specific mRNA transcripts were quantitatively analyzed by TaqManGene Expression assays (Thermo Fisher Scientific, Yokohama, Japan). The gene expression levels of Cd4 (Mm00442754_m1), Cd79b (Mm00434143_m1), H2-Aa (Mm00429211_m1), H2-Ab1 (Mm00439216_m1), Nfatc4(Mm00452375_m1) were measured. Total RNA was extracted using an RNase-Free DNase Set and a RNeasy Mini Kit (Qiagen, Hilden, Germany). The purity of total RNA was assessed by Bio photometer plus (Eppendorf, Hamburg, Germany). The cDNA libraries were obtained by reverse transcription-PCR using a High-Capacity CDNA Reverse Transcription Kit (\#4368813 Thermo Fisher Scientific, Yokohama, Japan). All specimens were detected twice, and arithmetic means were used for quantification. The data of arithmetic mean were normalized to Vic-labeled Actb mRNA (\#4352341E: pre-developed TaqMan Assay Reagents, Thermo Fisher Scientific, Yokohama, Japan).

\section{Effects of NFAT inhibitors}

To examine the role of NFATc 4 in the prophylactic effects of $(R)$-ketamine, the two inhibitors (NFAT inhibitor and CysA) of NFATc4 were used. The NFAT inhibitor $(10 \mu \mathrm{M}, 2 \mu$ l, i.c.v. $)$ or saline $(2 \mu$ l, i.c.v. $)$ was injected $60 \mathrm{~min}$ before i.p. administration of LPS (1.0 mg/kg) in mice. CysA ( $40 \mathrm{mg} / \mathrm{kg}$, i.p.) or vehicle (10\% DMSO, $10 \mathrm{ml} / \mathrm{kg}$, i.p.) was injected $60 \mathrm{~min}$ before i.p. administration of LPS $(1.0 \mathrm{mg} / \mathrm{kg})$ in mice. Subsequently, the behavioral tests such as locomotion test and FST were performed as described above.

\section{Viral vector preparation and injection}

The transfer plasmid [U6-shNfatc4 (short hairpin RNA against Nfatc4)-CAGGSEmGFP] was constructed by Invitrogen. The viral vectors were prepared as described previously [60]. Briefly, the AAV vectors were packaged using the AAV Helper Free Expression System (Cell Biolabs, Inc., San Diego, CA). The packaging plasmids (pAAV-DJ and pHelper) and transfer plasmid (pAAV-U6shRNA-CAGGS-EmGFP or pAAV- U6-CAGGS-EGFP) were transfected into HEK293T cells using the calcium phosphate method. After $48 \mathrm{~h}$ incubation, $A A V$ vector particles were obtained and purified by serial ultracentrifugation with cesium chloride. The purified particles were dialyzed with PBS containing $0.001 \%$ Pluronic F-68 (Sigma-Aldrich, St. Louis, MO), and then concentrated by ultrafiltration using an Amicon 10k MWCO filter (Merck Millipore, Darmstadet, Germany). The copy number of the viral genome (vg) was determined by the TaqMan Universal Master Mix II (Applied Biosystems, Foster City, CA). Realtime quantitative $\mathrm{PCR}$ was performed in duplicate samples using the StepOne real-time PCR system as follows: $95^{\circ} \mathrm{C}$ for $10 \mathrm{~min} ; 40$ cycles of $\left(95^{\circ} \mathrm{C}, 15 \mathrm{~s}\right.$, and $\left.60{ }^{\circ} \mathrm{C}, 1 \mathrm{~min}\right)$.

To induce gene expression in the mPFC, AAV DJ-CAGGS-Nfatc4-P2AEmGFP or AAV DJ-CAGGS-EGFP vectors $\left(1.0 \times 10^{12} \mathrm{vg} / \mathrm{ml}\right)$ were bilaterally injected into the mPFC ( $+1.7 \mathrm{AP}, \pm 0.4 \mathrm{ML},-1.8 \mathrm{DV})$ of $\mathrm{C} 57 \mathrm{BL} / 6$ male mice at 9 weeks old by microinjection tube connected to a micro-infusion pump $(1 \mu \mathrm{l} / \mathrm{site}, 0.5 \mu \mathrm{l} / \mathrm{min})$ [61]. Three weeks after injection, saline $(10 \mathrm{ml} / \mathrm{kg})$ or LPS $(1.0 \mathrm{mg} / \mathrm{kg})$ was administered i.p. to mice. Subsequently, behavioral tests such as locomotion test and FST were performed. After behavioral tests, the bilateral medial prefrontal cortex (mPFC) was collected rapidly and stored at $-80^{\circ} \mathrm{C}$ until bioanalysis. The weight of spleens was recorded immediately after spleen removal. 


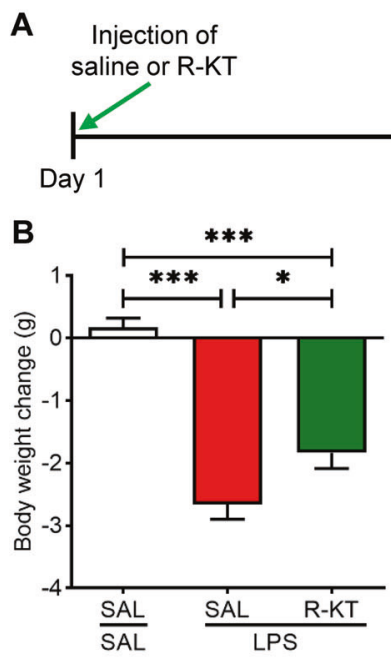

Injection of Behavioral Tests

Collection of plasma and spleens
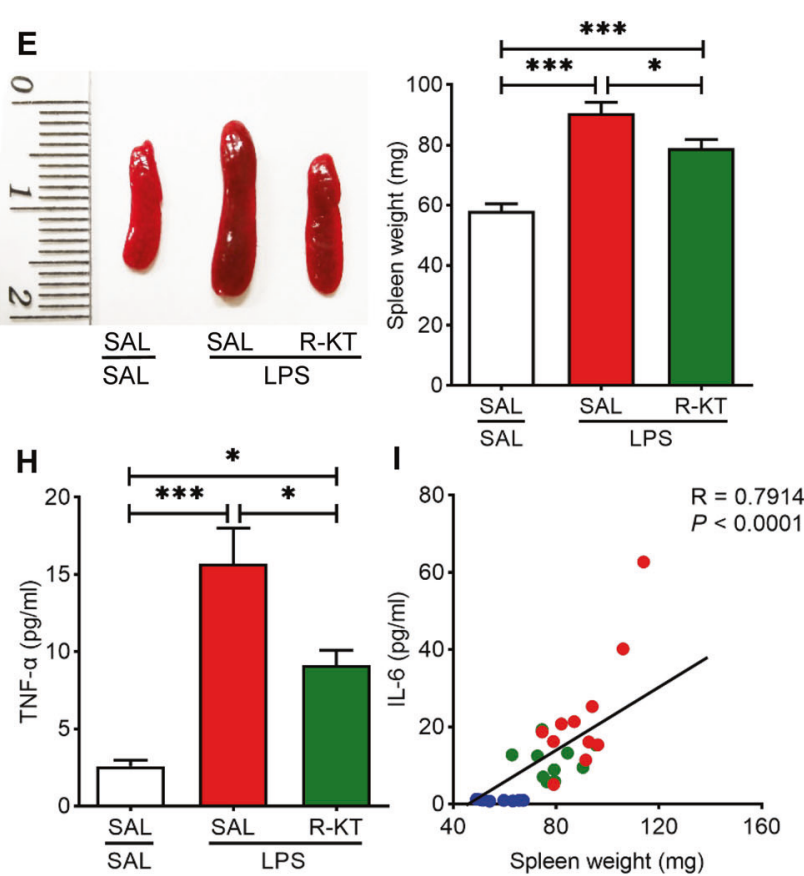

$\mathbf{F}$
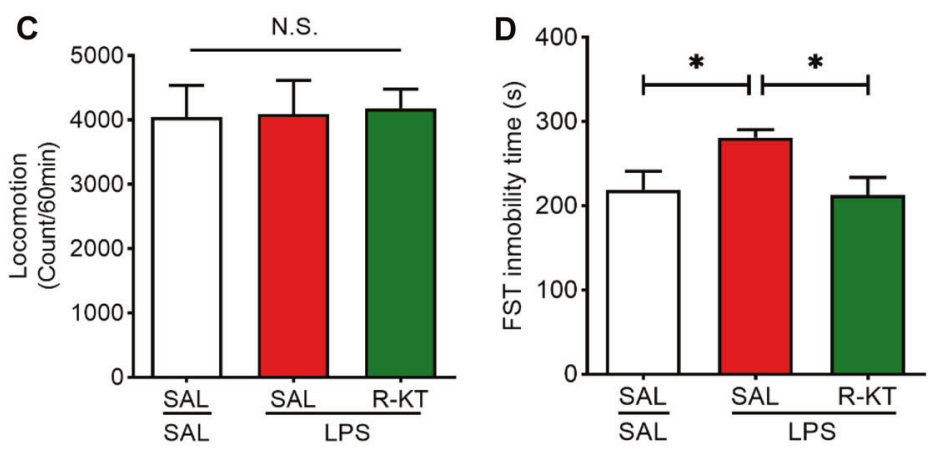

Fig. 1 Prophylactic effects of $(R)$-ketamine on depression-like phenotype, splenomegaly and inflammatory cytokines after LPS injection. A Treatment schedule. Adult mice were intraperitoneally (i.p.) injected with lipopolysaccharides (LPS, $1.0 \mathrm{mg} / \mathrm{kg}) \mathrm{or}$ saline (10 ml/kg). (R)ketamine $(10 \mathrm{mg} / \mathrm{kg})$ or saline $(10 \mathrm{ml} / \mathrm{kg})$ was i.p. injected to mice 6 days before LPS injection. Locomotion test and forced swimming test (FST) were performed 23 and $24 \mathrm{~h}$ after the injection of saline or LPS. Blood and spleens were collected after behavioral tests. B Body weight change (one way ANOVA: $F_{2,24}=41.19, P<0.0001$ ). C Locomotion test (one way ANOVA: $F_{2,24}=0.034, P=0.966$ ). $D$ FST (one way ANOVA: $F_{2,24}=4.738$, $P=0.018$ ). E Representative picture of spleen and spleen weight (one way ANOVA: $F_{2,27}=27.06, P<0.001$ ). $\mathbf{F}$ The ratio of spleen weight/body weight (one way ANOVA: $F_{2,27}=44.13, P<0.0001$ ). G Plasma levels of interleukin (IL)-6 (one way ANOVA: $F_{2,27}=12.24, P=0.0002$ ). $\mathbf{H}$ Plasma levels of tumor necrosis factor (TNF)- $\alpha$ (one way ANOVA: $F_{2,27}=17.08, P<0.0001$ ). I There was a positive correlation $(R=0.791, P<0.0001$ ) between spleen weight and plasma IL-6. (J): There was a positive correlation $(R=0.626, P=0.0002)$ between spleen weight and plasma TNF- $\alpha$. The data represent mean \pm S.E.M. $(n=8-11) .{ }^{*} P<0.05,{ }^{* * *} P<0.01,{ }^{* * *} P<0.0001$. N.S., not significant.

\section{Western blot analysis}

Detailed methods for Western blot analysis were shown in the supplemental information.

\section{Statistical analysis}

The data were shown as mean \pm standard error of the mean (S.E.M.). Analysis was performed using PASW Statistics 20 (formerly SPSS Statistics; SPSS). A test of homogeneity of variance for all animal data showed no significant difference. The data were analyzed using the one-way analysis of variance (ANOVA), followed by post-hoc Tukey test. The data using postmortem brain samples were analyzed using Mann-Whitney U-test. Correlation was determined by Pearson correlation. The $P$-values of less than 0.05 were considered statistically significant.

\section{RESULTS}

Prophylactic effects of $(R)$-ketamine on depression-like phenotype, splenomegaly, and systemic inflammation after LPS administration

Saline or LPS $(1.0 \mathrm{mg} / \mathrm{kg})$ was administered to mice 6 days after injection of saline or (R)-ketamine $(10 \mathrm{mg} / \mathrm{kg})$ (Fig. 1A). Body weight of mice was significantly decreased $24 \mathrm{~h}$ after LPS injection (Fig. 1B). Pretreatment with $(R)$-ketamine significantly attenuated LPS-induced body weight loss (Fig. 1B). There were no significant changes in the locomotor activity among the three groups (Fig. 1C). Pretreatment with (R)-ketamine significantly ameliorated LPS-induced increase in the immobility time of FST (Fig. 1D). In 
contrast, pretreatment with $(R)$-norketamine $(10 \mathrm{mg} / \mathrm{kg})$ or $(2 R, 6 R)$ HNK $(10 \mathrm{mg} / \mathrm{kg})$, two metabolites of $(R)$-ketamine, did not show prophylactic effects for body weight loss, splenomegaly and depression-like phenotype in LPS-treated mice (Figure S1).

We previously reported that LPS caused the splenomegaly and the increased ratio of spleen weight to body weight in the mice, and that spleen weight was associated with systemic inflammation [50]. Pretreatment with $(R)$-ketamine $(10 \mathrm{mg} / \mathrm{kg})$ significantly attenuated the splenomegaly and the increased ratio of spleen weight to body weight in mice after LPS administration (Fig. 1E, F). Pretreatment with $(R)$-ketamine significantly attenuated the increased blood levels of IL- 6 and TNF- $\alpha$ in the LPS-treated mice (Fig. 1G, H). There were significantly positive correlations between plasma IL-6 (or TNF-a) levels and spleen weight in the three groups (Fig. 1l, J). The data suggest that LPS-induced systemic inflammation might be related with spleen weight, consistent with our previous reports $[50,62]$.

\section{RNA-sequencing analysis of PFC samples}

To identify the novel molecular targets for the prophylactic effects of $(R)$-ketamine $(10 \mathrm{mg} / \mathrm{kg}, 6$ days before), we collected PFC samples $24 \mathrm{~h}$ after administration of LPS $(1.0 \mathrm{mg} / \mathrm{kg})$. We performed RNA-sequencing analysis of PFC samples from animals treated with either $(R)$-ketamine or saline (Fig. 2A). The canonical pathway results identified a total of 7 pathways. Among these pathways, the role of NFAT (nuclear factor of activated T cells) in regulation of immune response signaling pathway had the highest inhibition score, and 5 genes including CD4, CD79b, H2-ab1, H2-aa, Nfatc4 are related to NFAT pathway (Fig. 2B). Subsequent diseases and functions analysis shows that the differentially expressed genes were associated with inflammation (Fig. 2C). In the network analysis, we observed 18 genes, and the top functions of this network included cell morphology, cell-to-cell signaling interaction, and immunoglobulin (Fig. 2D).

Next, we measured gene expression of several genes (Nfatc4, $\mathrm{Cd} 4, \mathrm{Cd} 79 b, \mathrm{H2}-\mathrm{ab1}$, and H2-aa) for NFATc4 signaling in the PFC samples. We found increased expression of Nfatc4, $\mathrm{Cd} 4, \mathrm{Cd} 796, \mathrm{H2}$ $A b 1$, and $H 2-A a$ in the PFC from LPS-treated mice (Fig. 3A, E-H).
Pretreatment with $(R)$-ketamine $(10 \mathrm{mg} / \mathrm{kg})$ significantly attenuated the increased expression of these genes in the PFC of LPStreated mice (Fig. 3A, E-H). There were positive correlations between expression of Nfatc4 in the PFC and spleen weight (or blood levels of IL-6, TNF-a) from three groups (Fig. 3B, C), indicating that Nfatc4 expression in the PFC may be associated with systemic inflammation.

Western blot analysis showed that pretreatment with $(R)$ ketamine $(10 \mathrm{mg} / \mathrm{kg})$ significantly ameliorated the reduction of postsynaptic density protein 95 (PSD-95) in the PFC of LPS-treated mice (Fig. 3I). Furthermore, Western blot analysis using postmortem brain samples showed that the levels of NFATc4 in the parietal cortex from MDD patients were significantly higher than those of controls (Fig. 3J).

Pretreatment with $(R)$-ketamine $(10 \mathrm{mg} / \mathrm{kg})$ significantly attenuated splenomegaly and increased levels of IL- 6 and TNF- $a$ in the LPS-treated mice (Figure S2). Furthermore, there were positive correlations between spleen weight (or IL-6, TNF- $a$ ) and expression of several genes (i.e., $C d 4, C d 79 b, H 2-A b 1$ ) in the PFC from three groups (Figure S2). The data suggest that gene expression of NFATc4 signaling in the PFC may be associated with systemic inflammation.

\section{Effects of NFAT inhibitors on LPS-induced depression-like phenotype}

To study the role of NFATc4 signaling in LPS-induced depressionlike phenotype, two NFAT inhibitors (NFAT inhibitor and CysA) were used (Fig. 4A, H). Pretreatment with the NFAT inhibitor $(10 \mu \mathrm{M}, 2 \mu \mathrm{l}$, i.c.v., $60 \mathrm{~min})$ significantly attenuated LPS-induced increase in the immobility time of FST (Fig. 4D), without significant effects on LPS-induced body weight loss, splenomegaly, and locomotion (Fig. 4B-E). The NFAT inhibitor significantly attenuated increased blood levels of IL-6 in the LPS-treated mice (Fig. 4F). The NFAT inhibitor slightly attenuated increased blood levels of TNF-a in the LPS-treated mice although statistical analysis did not reach significance (Fig. 4G).

Furthermore, pretreatment with NFAT inhibitor CysA $(40 \mathrm{mg} / \mathrm{kg}$, i.p., $60 \mathrm{~min}$ ) significantly inhibited LPS-induced increase in the
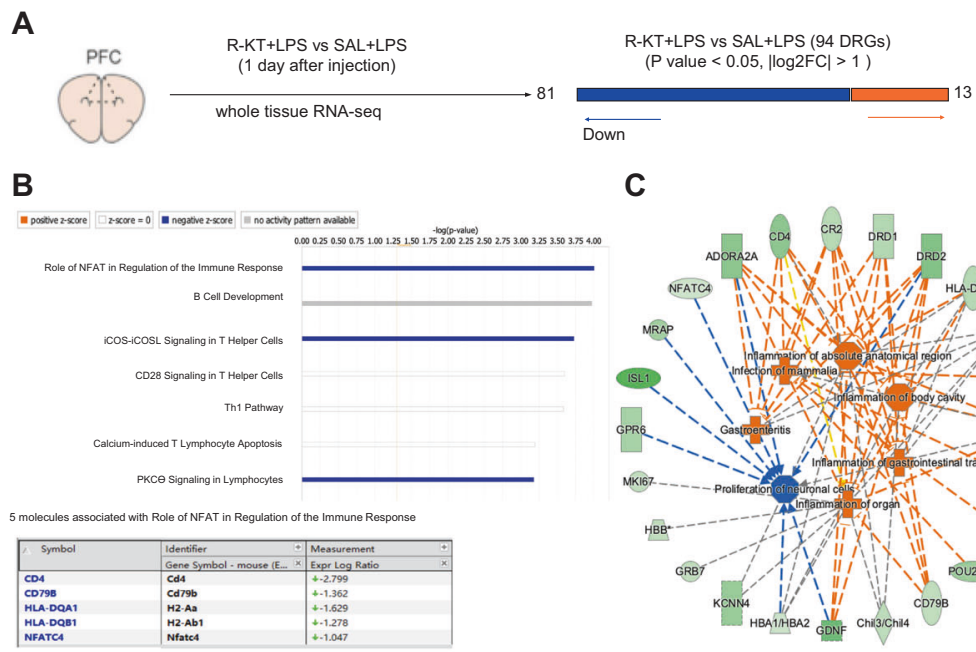

C

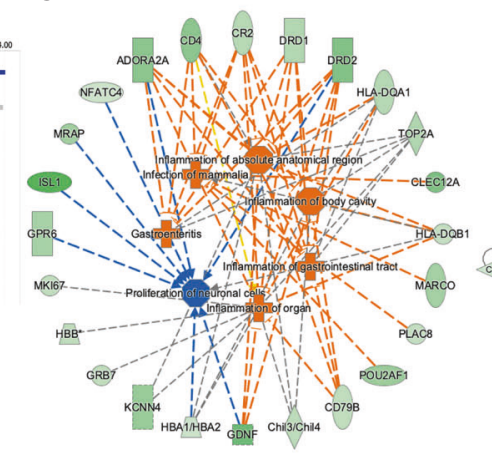

Fig. 2 Canonical pathway, protein functional network and diseases analysis for differentially genes in the PFC after LPS injection. A Adult mice were i.p. injected with LPS $(1.0 \mathrm{mg} / \mathrm{kg}) 6$ days after i.p. administration of $(R)$-ketamine $(10 \mathrm{mg} / \mathrm{kg})$ or saline $(10 \mathrm{ml} / \mathrm{kg})$. For RNAsequencing, PFC samples were collected $24 \mathrm{~h}$ after injection of LPS. B Top 7 canonical pathways altered in the PFC were identified by Ingenuity Pathway Analysis (IPA). The role of NFAT in regulation of the immune response signaling pathway had the highest inhibition scores $(P=9.85 \mathrm{E}-05, \mathrm{z}$-score $=-2.236)$. C IPA constructs identified relationships between the differentially expressed genes and associated disorders. D The most significant molecular network by IPA pathway enrichment analysis. IPA Z-score indicates whether the pathway is predicated to be inhibited (blue) or activated (red). In some cases, activation or inhibition cannot be predicated (gray). The shapes of the proteins imply their molecular classes as outlined in the legend. Solid lines indicate direct interaction whereas dashed line correspond to indirect relationship among the interacting proteins. The arrows indicate modulatory effect of a protein on its interacting proteins. 


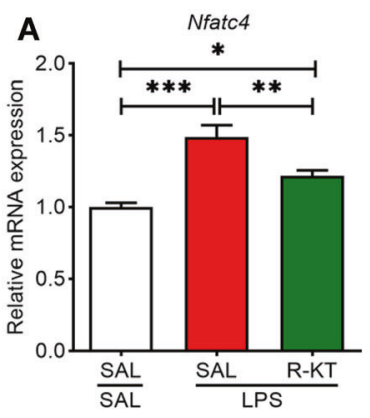

E

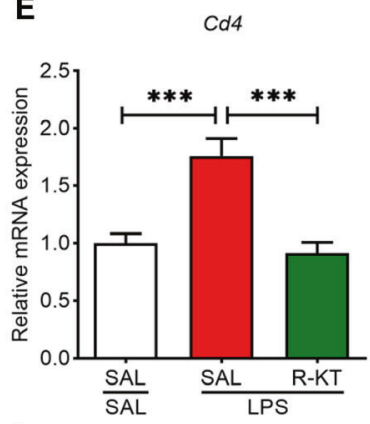

I

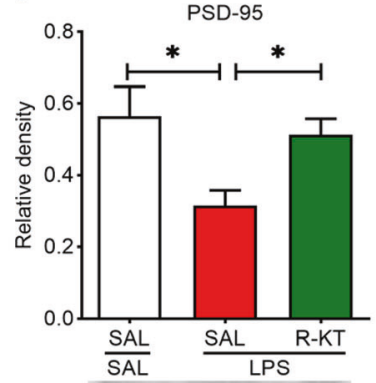

PSD-95

B-actin

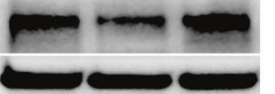

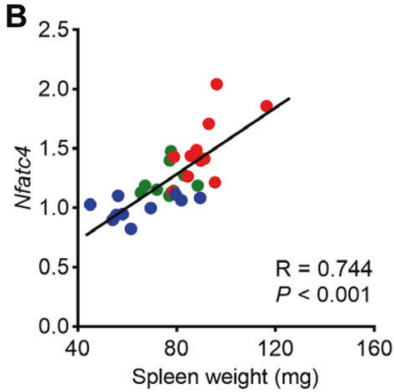

F

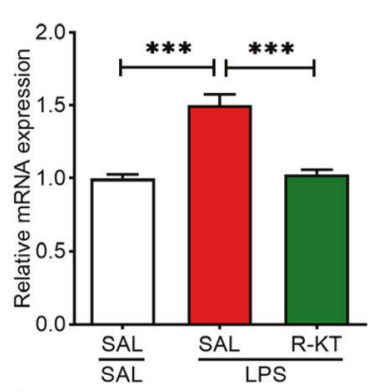

J

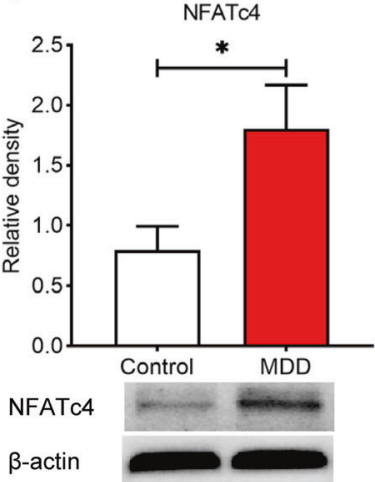

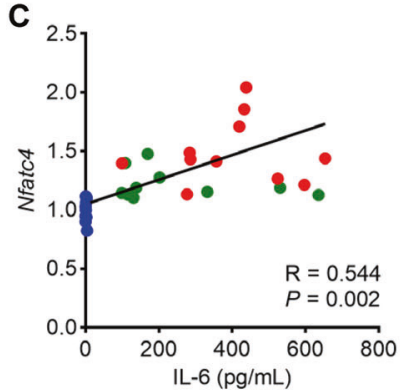

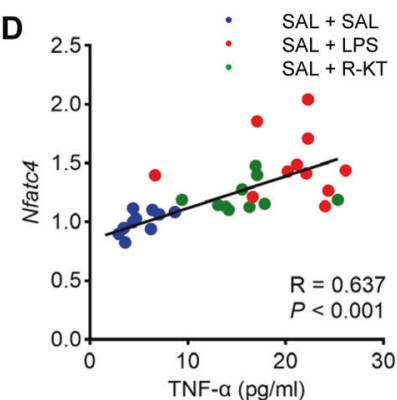

G
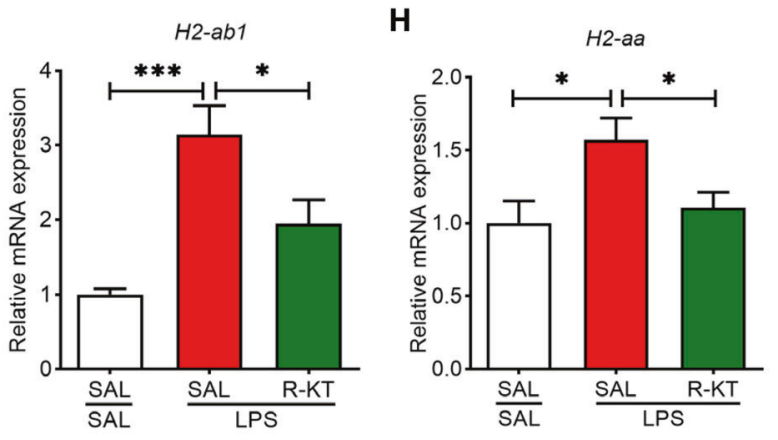

Fig. 3 Prophylactic effects of $(\boldsymbol{R})$-ketamine on the expression of NFATc4 in the PFC after LPS injection. A Nfatc4 mRNA in the PFC (one way ANOVA: $\left.F_{2,28}=17.84, P<0.0001\right)$. B There was a positive correlation $(R=0.744, P<0.0001)$ between spleen weight and Nfatc4 mRNA in the PFC. C There was a positive correlation $(R=0.544, P=0.002)$ between plasma interleukin (IL)- 6 and Nfatc4 mRNA in the PFC. D There was a positive correlation $(R=0.637, P<0.0001)$ between plasma tumor necrosis factor (TNF)- $\alpha$ and Nfatc4 mRNA in the PFC. E Cd4 mRNA in the PFC (one way ANOVA: $F_{2,28}=16.16, P<0.0001$ ). $\mathbf{F} C d 79 b$ mRNA in the PFC (one way ANOVA: $F_{2,28}=30.40, P<0.0001$ ). $\mathbf{G} H 2-a b 1 \mathrm{mRNA}$ in the PFC (one way ANOVA: $F_{2,28}=12.81, P=0.0001$ ). $\mathbf{H ~ H 2}$-aa mRNA in the PFC (one way ANOVA: $F_{2,28}=5.617, P=0.009$ ). I The protein expression of PSD-95 in the PFC (one way ANOVA: $\left.F_{2,27}=5.506, P=0.010\right)$. The data represent mean \pm S.E.M. $(n=9-11) .{ }^{*} P<0.05,{ }^{* * *} P<0.01,{ }^{* * *} P<0.001$. J The protein expression of NFATc4 in the parietal cortex from controls $(n=15)$ and MDD patients $(n=15)($ Man-Whitney U-test: $U=60.00$, $P=0.030)$. The data represent mean \pm S.E.M. $(n=15) .{ }^{*} P<0.05$.

immobility time of FST (Fig. 4J) without significant effects in the body weight loss (Fig. 4l). These data show that similar to $(R)$ ketamine, NFAT inhibitors can show prophylactic effects for LPSinduced depression-like behavior.

\section{Effects of NFATc4 knockdown on LPS-induced depression-like phenotype}

We further studied the impact of NFATc4 knockdown on LPSinduced depression-like phenotype, splenomegaly, and increased plasma inflammatory cytokines. AAV-U6-shNfatc4-CAGGS-EmGFP or AAV-CAGGS-EGFP were stereotaxic injected into the mPFC to induce knockdown of NFATc4 in the mPFC (Fig. 5A). Western blotting analysis confirmed the knockdown efficiency of NFATC4 and p-NFATC4 in the mPFC (Fig. 5C, D). NFATc4 knockdown significantly ameliorated LPS-induced increase in the immobility time of FST (Fig. 5F). In contrast, NFATc4 knockdown in the mPFC did not affect body weight loss (Fig. 5E) and splenomegaly in the
LPS-treated mice (Fig. 5G). NFATc4 knockdown in the mPFC significantly attenuated increased levels of IL-6, but not TNF-a, in the LPS-treated mice (Fig. 5H, I). The data suggest that NFATc4 in the mPFC plays a role in depression-like phenotype and increases in blood levels of IL-6 of LPS-treated mice.

\section{The roles of TrkB in the prophylactic effects of $(R)$-ketamine in LPS model}

We previously reported the role of brain-derived neurotrophic factor (BDNF) and its receptor, tropomyosin-receptor-kinase B (TrkB) signaling in the beneficial actions of $(R)$-ketamine $[32,37,53-56]$. To investigate the roles of BDNF-TrkB signaling in the prophylactic effects of $(R)$-ketamine on LPS-induced depression-like phenotype, TrkB antagonist ANA-12 $(0.5 \mathrm{mg} / \mathrm{kg})$ was injected to mice $30 \mathrm{~min}$ before injection of $(R)$-ketamine (Figure S3). There were no changes in locomotion among the five groups (Figure S3B). Pretreatment with ANA-12 significantly blocked the antidepressant-like effects of 
A
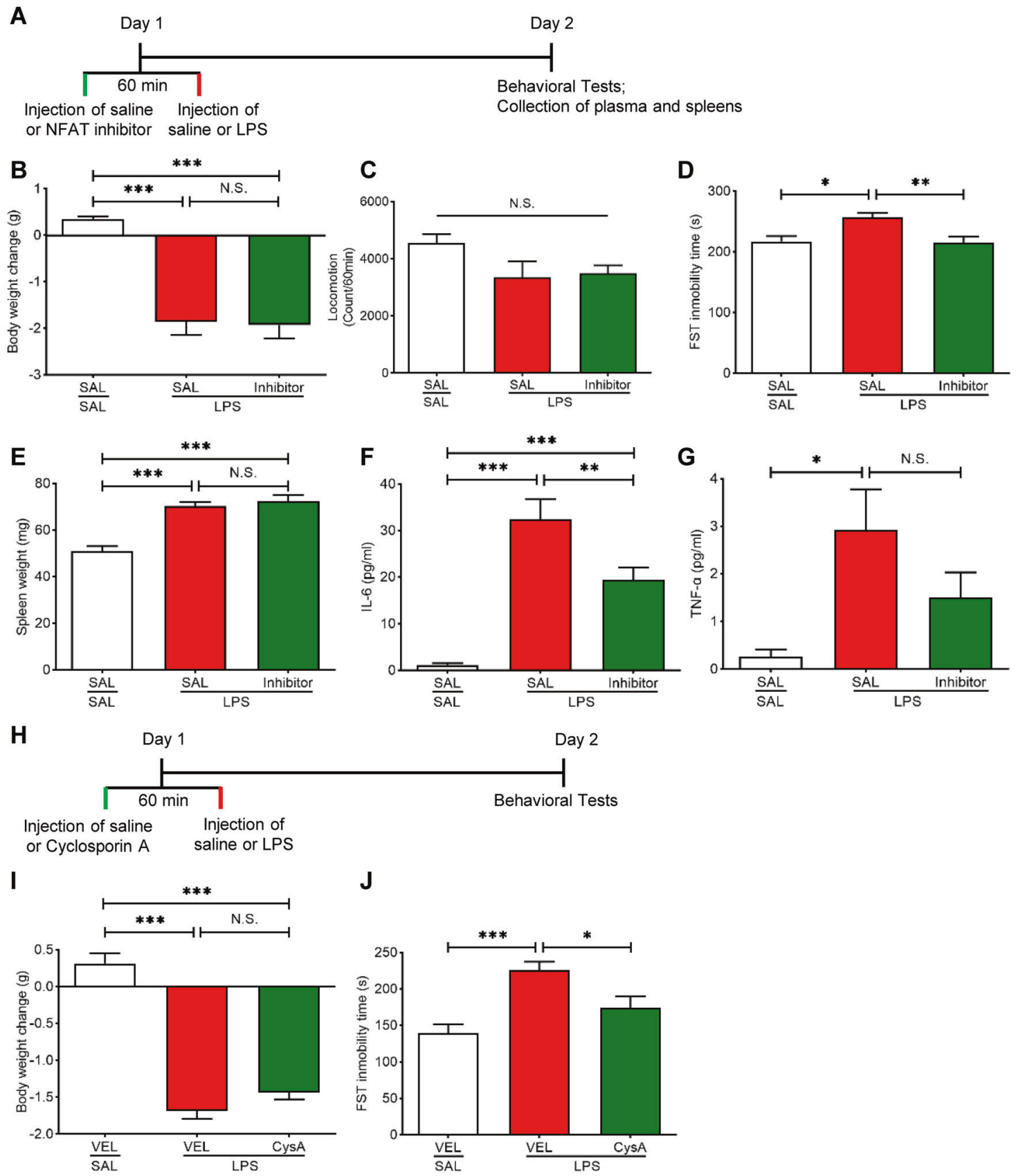

Fig. 4 Effects of NFAT inhibitors on depression-like phenotype, spleen weight and pro-inflammatory cytokines after LPS injection. A Treatment schedule. Mice were i.p. injected with LPS $(1.0 \mathrm{mg} / \mathrm{kg})$ or saline $(10 \mathrm{ml} / \mathrm{kg})$. NFAT inhibitor $(10 \mu \mathrm{M}, 2 \mu \mathrm{l})$ or saline $(2 \mu \mathrm{l})$ was administered i.c.v. to mice $60 \mathrm{~min}$ prior to LPS injection. Locomotion test and forced swimming test (FST) were performed 23 and $24 \mathrm{~h}$ after the injection of saline or LPS, respectively. Blood and spleens were collected after behavioral tests. $\mathbf{B}$ Body weight change (one way ANOVA: $F_{229}=$ 27.72, $P<0.0001$ ). C Locomotion test (one way ANOVA: $F_{2,29}=2.589, P=0.092$ ). D FST (one way ANOVA: $F_{2,29}=6.486, P=0.005$ ). E Spleen weight (one way ANOVA: $F_{2,28}=26.41, P<0.0001$ ). F Plasma levels of IL-6 (one way ANOVA: $F_{2,28}=28.67, P<0.0001$ ). G Plasma levels of TNF- $\alpha$ (one way ANOVA: $\left.F_{2,28}=5.013, P=0.014\right)$. H Treatment schedule. Mice were i.p. injected with LPS (1.0 mg/kg) or saline (10 ml $\left./ \mathrm{kg}\right)$. Cyclosporin A (CysA: $40 \mathrm{mg} / \mathrm{kg})$ or vehicle $(10 \%$ DMSO, $10 \mathrm{ml} / \mathrm{kg}$ ) was i.p. injected to mice $60 \mathrm{~min}$ prior to LPS injection. Locomotion test and FST were performed 23 and $24 \mathrm{~h}$ after the injection of saline or LPS, respectively. I Body weight change (one way ANOVA: $F_{2,27}=90.99, P<0.0001$ ). J FST (one way ANOVA: $\left.F_{2,27}=10.86, P=0.0003\right)$. The data represent mean \pm S.E.M. $(n=10-12) . P<0.05,{ }^{* *} P<0.01,{ }^{* * *} P<0.001$. N.S., not significant.

$(R)$-ketamine in the LPS-treated mice (Figure S3C). Our data suggest that $(R)$-ketamine shows prophylactic effects on LPS-induced depression-like phenotype via BDNF-TrkB signaling.

\section{DISCUSSION}

The main findings of this study are as follows: First, pretreatment (6 days) with (R)-ketamine could ameliorate LPS-induced depression-like phenotype, splenomegaly, and increased blood levels of pro-inflammatory cytokines in mice. In contrast, $(R)$ norketamine and $(2 R, 6 R)$-HNK did not show prophylactic effects in the same model. Second, RNA-sequencing and IPA revealed the role of NFATc4 signaling in the PFC for prophylactic effects of $(R)$ ketamine in the LPS-induced model. RT-PCR revealed the increased expression of several genes (Nfatc4, Cd4, Cd79b, H2$A b 1, H 2-A a)$ of NFATC4 signaling in the PFC of LPS-treated mice. 
A

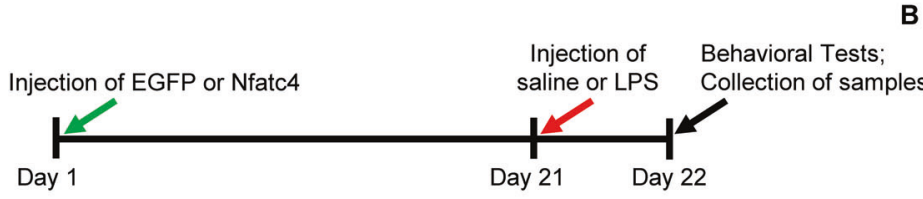

B
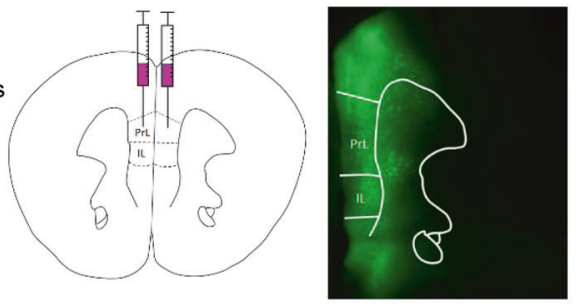

EGFP: AAV-CAGGS-EGFP

Nfatc4: AAV-U6-shNfatc4-CAGGS-EmGFP

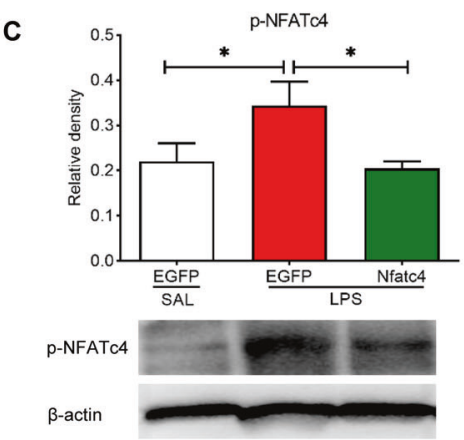

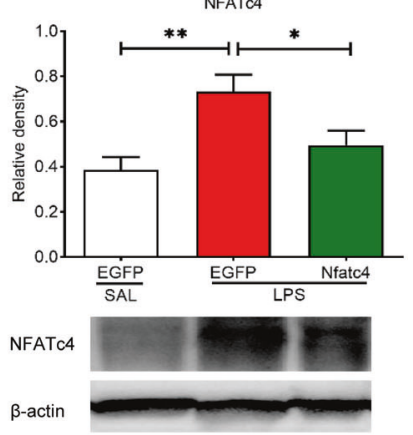

E

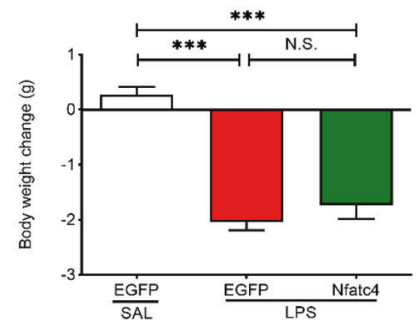

$\mathbf{F}$

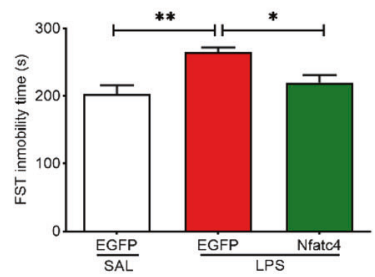

G

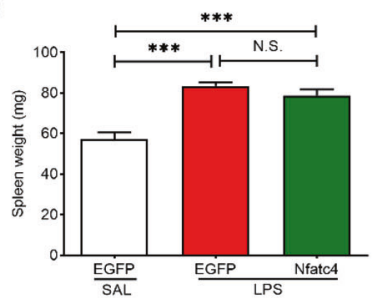

H

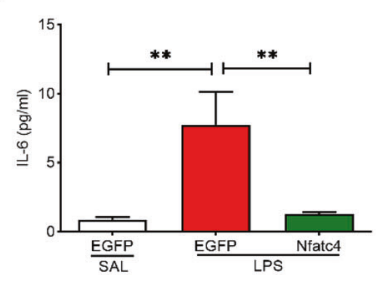

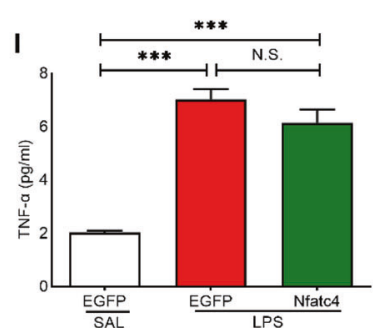

Fig. 5 Effects of NFATc4 knockdown on depression-like phenotype, spleen weight and inflammatory cytokines after LPS injection. A Treatment schedule. AAV-U6-shNfatc4-CAGGS-EmGFP or AAV-CAGGS-EGFP was injected bilaterally to mPFC 21 days prior to saline (10 ml/ $\mathrm{kg})$ or LPS $(1.0 \mathrm{mg} / \mathrm{kg})$ injection. Locomotion test and FST were performed 23 and $24 \mathrm{~h}$ after the injection of saline or LPS, respectively. Blood, spleen and mPFC were collected after behavioral tests. B Schematic of AAV-mediated Nfatc4 down expression in the mPFC. The diagram shows the AAV constructs and stereotaxic injection of AAV into the mPFC. C The protein expression of phosphorylated NFATc4 (p-NFATc4) in the mPFC (one way ANOVA: $F_{2,26}=5.440, P=0.011$ ). $D$ The protein expression of total NFATc4 in the mPFC (one way ANOVA: $F_{2,26}=6.673, P=$ 0.005). E Body weight change (one way ANOVA: $F_{2,26}=36.65, P<0.0001$ ). F FST (one way ANOVA: $F_{2,26}=8.409, P=0.002$ ). $\mathbf{G}$ Spleen weight (one way ANOVA: $F_{2,26}=23.94, P<0.0001$ ). H Plasma levels of IL-6 (one way ANOVA: $F_{2,26}=8.580, P=0.001$ ). I Plasma levels of TNF- $\alpha$ (one way ANOVA: $\left.F_{2,26}=79.13, P<0.0001\right)$. The data represent mean \pm S.E.M. $(\mathrm{n}=9-11) .{ }^{*} P<0.05,{ }^{* * *} P<0.01,{ }^{* * *} P<0.001$. N.S., not significant.

Furthermore, $(R)$-ketamine significantly attenuated the increased expression of these genes in the PFC of LPS-treated mice. There were positive correlations between the expression of Nfatc 4 mRNA in the PFC and spleen weight (or blood levels of IL-6, TNF-a) from three groups. In addition, we found the increased expression of NFATC4 protein in the parietal cortex of MDD patients compared to controls. Third, pharmacological inhibitors of NFAT showed prophylactic antidepressant-like effects in the LPS-treated mice, indicating a role of NFAT signaling in the prophylactic antidepressant-like effects of $(R)$-ketamine. Fourth, knockdown of Nfatc4 gene in the MPFC by AAV blocked LPS-induced increases in the immobility time of FST, suggesting a role of NFATc4 in the mPFC in the prophylactic effects of $(R)$-ketamine. Lastly, pretreatment with TrkB inhibitor ANA-12 significantly blocked prophylactic effects of $(R)$-ketamine in the LPS-treated mice. Overall, it appears likely that $(R)$-ketamine can exert sustained prophylactic antidepressant-like effects by decreasing NFATc4 signaling in the PFC.

We found that $(R)$-ketamine showed a sustained (6 days) prophylactic effect in inflammation model of depression; however, $(R)$-norketamine and $(2 R, 6 R)$-HNK did not show prophylactic effects in the same model. We previously reported that $(R)$ norketamine and $(2 R, 6 R)$-HNK did not show antidepressant-like effects in LPS-induced inflammation, LH, and CSDS models of depression $[35,63]$. Therefore, it is likely that $(R)$-ketamine itself, but not these metabolites, could have prophylactic effects in LPStreated mice.
Despite of short half-life of $(R)$-ketamine in rodents [33, 34], $(R)$ ketamine showed sustained (6 days) prophylactic effects in LPStreated mice. The data suggest that altered signaling pathway induced by $(R)$-ketamine may play a role in its prophylactic effects. RNA-seq analysis and IPA identified a role of NFATc4 signaling in the PFC for prophylactic effects of $(R)$-ketamine. Using two NFAT inhibitors and AAV for Nfatc4, we found that NFATC4 signaling in the mPFC might play a role in the sustained prophylactic effects of $(R)$-ketamine for LPS-induced depression.

The transcription factor NFATc4 is localized in neuron, but not astrocyte, microglia, and oligodendrocyte, in the brain [64]. Interestingly, NFATc4 is demonstrated to play a key role in BDNF-mediated synaptic plasticity, resulting in long-term changes in neuronal functions $[52,65]$. In this study, we found positive correlations between Nfatc4 gene expression in the PFC and spleen weight (or pro-inflammatory cytokines). Considering the crucial role of NFATc4 in immune system $[66,67]$, it seems that NFATc4 in the PFC may regulate systemic inflammation in mice via brain-body crosstalk. However, the precise mechanisms underlying $(R)$-ketamine-induced reduction of NFATc4 signaling are currently unknown.

We previously reported that LPS caused splenomegaly in mice, and that spleen weight of LPS-treated mice was associated with blood levels of pro-inflammatory cytokines in these mice [50, 62]. In this study, pretreatment with $(R)$-ketamine ameliorated splenomegaly in the LPS-treated mice through anti-inflammatory 
effects although $(R)$-ketamine was washout from the body. In contrast, the NFAT inhibitors or AAV in the mPFC did not affect splenomegaly in the LPS-treated mice. It is unlikely that gene knockdown of NFATC4 by AAV in the mPFC can affect LPS-induced splenomegaly in mice. Thus, it seems that other mechanisms except NFATc4 may play a role in the effects of $(R)$-ketamine on the LPS-induced splenomegaly. In contrast, gene knockdown of NFATC4 by AAV in the MPFC significantly attenuated increased blood levels of IL-6 in the LPS-treated mice via brain-body communication. Precise mechanisms underlying the relationship between gene knockdown of Nfatc4 in the MPFC and blood levels of IL-6 remain unclear. Recently, we reported that splenomegaly in CSDS susceptible mice could be normalized after single injection of $(R)$-ketamine [68]. It is possible that brain-spleen axis may play a role in the beneficial effects of $(R)$-ketamine on depression-like phenotype and splenomegaly $[19,22]$, although further study is needed.

Depression has high rate of recurrence, resulting in significant personal and public health consequences [69]. Therefore, prevention of recurrence using cognitive behavioral therapy and pharmacological treatment is extremely important. Given potent prophylactic effects of $(R)$-ketamine, it is possible that $(R)$-ketamine might prevent the recurrence in depressed patients. It is, therefore, of interest to investigate whether $(R)$-ketamine can reduce the recurrent rate in depressed patients.

In conclusion, this study shows that NFATc4 signaling in the PFC might contribute to the prophylactic effects of $(R)$-ketamine in inflammation model of depression. It is likely that $(R)$-ketamine or NFATc4 inhibitors may produce prophylactic effects for inflammation-related depression in humans.

\section{DATA AVAILABILITY}

The RNA sequencing data have been deposited to the NCBI Sequence Read Archive and are available at the accession number PRJNA768662.

\section{REFERENCES}

1. Krystal JH, Abdallah CG, Sanacora G, Charney D, Duman RS. Ketamine: a paradigm shift for depression research and treatment. Neuron. 2019;101:774-8.

2. Berman RM, Cappiello A, Anand A, Oren DA, Heninger GR, Charney DS, et al. Antidepressant effects of ketamine in depressed patients. Biol Psychiatry. 2000;47:351-4

3. Zarate CA Jr, Singh JB, Carlson PJ, Brutsche NE, Ameli R, Luckenbaugh DA, et al. A randomized trial of an $\mathrm{N}$-methyl-D-aspartate antagonist in treatment-resistant major depression. Arch Gen Psychiatry. 2006;63:856-64.

4. Diazgranados N, Ibrahim L, Brutsche NE, Newberg A, Kronstein P, Khalife S, et al. A randomized add-on trial of an $\mathrm{N}$-methyl-D-aspartate antagonist in treatmentresistant bipolar depression. Arch Gen Psychiatry. 2010;67:793-802.

5. Zarate CA Jr, Brutsche NE, Ibrahim L, Franco-Chaves J, Diazgranados N, Cravchik A, et al. Replication of ketamine's antidepressant efficacy in bipolar depression: a randomized controlled add-on trial. Biol Psychiatry. 2012;71:939-46.

6. Murrough JW, losifescu DV, Chang LC, Al Jurdi RK, Green CE, Perez AM, et al. Antidepressant efficacy of ketamine in treatment-resistant major depression: a two-site randomized controlled trial. Am J Psychiatry. 2013;170:1134-42.

7. Singh JB, Fedgchin M, Daly EJ, De Boer P, Cooper K, Lim P, et al. A double-blind, randomized, placebo-controlled, dose-frequency study of intravenous ketamine in patients with treatment-resistant depression. Am J Psychiatry. 2016;173: 816-26.

8. Su TP, Chen MH, Li CT, Lin WC, Hong CJ, Gueorguieva R, et al. Dose-related effects of adjunctive ketamine in Taiwanese patients with treatment-resistant depression. Neuropsychopharmacology. 2017;42:2482-92.

9. Phillips JL, Norris S, Talbot J, Birmingham M, Hatchard T, Ortiz A, et al. Single, repeated, and maintenance ketamine infusions for treatment-resistant depression: a randomized controlled trial. Am J Psychiatry. 2019;176:401-9.

10. Fava M, Freeman MP, Flynn M, Judge H, Hoeppner BB, Cusin C, et al. Doubleblind, placebo-controlled, dose-ranging trial of intravenous ketamine as adjunctive therapy in treatment-resistant depression (TRD). Mol Psychiatry. 2020;25:1592-603.

11. Newport DJ, Carpenter LL, McDonald WM, Potash JB, Tohen M, Nemeroff CB. APA Council of Research Task Force on Novel Biomarkers and Treatments. Ketamine and other NMDA antagonists: early clinical trials and possible mechanisms in depression. Am J Psychiatry. 2015;172:950-66.

12. Kishimoto T, Chawla JM, Hagi K, Zarate CA, Kane JM, Bauer M, et al. Single-dose infusion ketamine and non-ketamine $N$-methyl-D-aspartate receptor antagonists for unipolar and bipolar depression: a meta-analysis of efficacy, safety, and time trajectories. Psychol Med. 2016;46:1459-72.

13. Zheng W, Zhou YL, Liu WJ, Wang CY, Zhan YN, Li HQ, et al. Rapid and longer-term antidepressant effects of repeated-dose intravenous ketamine for patients with unipolar and bipolar depression. Psychiatry Res. 2018;106:61-8.

14. Murrough JW, Abdallah CG, Mathew SJ. Targeting glutamate signaling in depression: progress and prospects. Nat Rev Drug Discov. 2017;16:472-86.

15. Gould TD, Zarate CA Jr, Thompson SM. Molecular pharmacology and neurobiology of rapid-acting antidepressants. Annu Rev Pharmacol Toxicol. 2019;59:213-36.

16. Hashimoto K. Rapid-acting antidepressant ketamine, its metabolites and other candidates: a historical overview and future perspective. Psychiatry Clin Neurosci. 2019;73:613-27.

17. Yang C, Yang J, Luo A, Hashimoto K. Molecular and cellular mechanisms underlying the antidepressant effects of ketamine enantiomers and its metabolites. Transl Psychiatry. 2019;9:280.

18. Zhang K, Hashimoto K. An update on ketamine and its two enantiomers as rapidacting antidepressants. Expert Rev Neurother. 2019;19:83-92.

19. Hashimoto K. Molecular mechanisms of the rapid-acting and long-lasting antidepressant actions of $(R)$-ketamine. Biochem Pharmacol. 2020;177:113935.

20. Wei Y, Chang L, Hashimoto K. A historical review of antidepressant effects of ketamine and its enantiomers. Pharmacol Biochem Behav. 2020;190:172870.

21. Castren E, Monteggia LM. Brain-derived neurotrophic factor signaling in depression and antidepressant action. Biol Psychiatry. 2021;90:128-36.

22. Wei $Y$, Chang L, Hashimoto $K$, Molecular mechanisms underlying the antidepressant actions of arketamine: beyond the NMDA receptor. Mol Psychiatry. 2021. https://doi.org/10.1038/s41380-021-01121-1.

23. Brachman RA, McGowan JC, Perusini JN, Lim SC, Pham TH, Faye C, et al. Ketamine as a prophylactic against stress-induced depressive-like behavior. Biol Psychiatry. 2016;79:776-86.

24. Mastrodonato A, Cohensedgh O, LaGamma CT, McGowan JC, Hunsberger HC, Denny CA. Prophylactic $(R, S)$-ketamine selectively protects against inflammatory stressors. Behav Brain Res. 2020;378:112238.

25. McGowan JC, LaGamma CT, Lim SC, Tsitsiklis M, Neria Y, Brachman RA, et al. Prophylactic ketamine attenuates learned fear. Neuropsychopharmacology. 2017;42:1577-89.

26. McGowan JC, Hill C, Mastrodonato A, LaGamma CT, Kitayev A, Brachman RA, et al. Prophylactic ketamine alters nucleotide and neurotransmitter metabolism in brain and plasma following stress. Neuropsychopharmacology. 2018;43:1813-21.

27. Mastrodonato A, Martinez R, Pavlova IP, LaGamma CT, Brachman RA, Robison AJ, et al. Ventral CA3 activation mediates prophylactic ketamine efficacy against stress-induced depressive-like behavior. Biol Psychiatry. 2018;84:846-56.

28. Parise EM, Parise LF, Sial OK, Cardona-Acosta AM, Gyles TM, Juarez B, et al. The resilient phenotype induced by prophylactic ketamine exposure during adolescence is mediated by the ventral tegmental area-nucleus accumbens pathway. Biol Psychiatry. 2021;90:482-93.

29. Ma JH, Wang SY, Yu HY, Li DY, Luo SC, Zheng SS, et al. Prophylactic use of ketamine reduces postpartum depression in Chinese women undergoing cesarean section. Psychiatry Res. 2019;279:252-8.

30. Feder A, Rutter SB, Schiller D, Charney DS. The emergence of ketamine as a novel treatment for posttraumatic stress disorder. Adv Pharm. 2020;89:261-86.

31. Zhang JC, Li SX, Hashimoto K. R(-)-ketamine shows greater potency and longer lasting antidepressant effects than $S(+)$-ketamine. Pharmacol Biochem Behav. 2014;116:137-41.

32. Yang C, Shirayama Y, Zhang JC, Ren Q, Yao W, Ma M, et al. $R$-ketamine: a rapidonset and sustained antidepressant without psychotomimetic side effects. Transl Psychiatry. 2015;5:e632.

33. Zanos $\mathrm{P}$, Moaddel R, Morris PJ, Georgiou P, Fischell J, Elmer Gl, et al. NMDAR inhibition-independent antidepressant actions of ketamine metabolites. Nature. 2016;533:481-6.

34. Fukumoto K, Toki H, lijima M, Hashihayata T, Yamaguchi J, Hashimoto K, et al. Antidepressant potential of $(R)$-ketamine in rodent models: comparison with (S)ketamine. J Pharmacol Exp Ther. 2017;361:9-16.

35. Yang C, Qu Y, Abe M, Nozawa D, Chaki S, Hashimoto K. (R)-Ketamine shows greater potency and longer lasting antidepressant effects than its metabolite (2R,6R)-hydroxynorketamine. Biol Psychiatry. 2017;82:e43-e44.

36. Yang C, Qu Y, Fujita Y, Ren Q, Ma M, Dong C, et al. Possible role of the gut microbiota-brain axis in the antidepressant effects of $(R)$-ketamine in a social defeat stress model. Transl Psychiatry. 2017;7:1294.

37. Yang C, Ren Q, Qu Y, Zhang JC, Ma M, Dong C, et al. Mechanistic target of rapamycin-independent antidepressant effects of $(R)$-ketamine in a social defeat stress model. Biol Psychiatry. 2018;83:18-28. 
38. Chang L, Zhang K, Pu Y, Qu Y, Wang SM, Xiong Z, et al. Comparison of antidepressant and side effects in mice after intranasal administration of $(R, S)$-ketamine, $(R)$-ketamine, and (S)-ketamine. Pharmacol Biochem Behav. 2019;181:53-9.

39. Zhang K, Yang C, Chang L, Sakamoto A, Suzuki T, Fujita Y, et al. Essential role of microglial transforming growth factor- $\beta 1$ in antidepressant actions of $(R)$-ketamine and the novel antidepressant TGF- $\beta 1$. Transl Psychiatry. 2020;10:32.

40. Zhu J, Hawkins E, Phillips K, Deshpande LS. Assessment of ketamine and its enantiomers in an organophosphate-based rat model for features of Gulf War illness. Int J Environ Res Public Health. 2020;17:4710.

41. Rafało-Ulińska A, Pałucha-Poniewiera A. The effectiveness of $(R)$-ketamine and its mechanism of action differ from those of (S)-ketamine in a chronic unpredictable mild stress model of depression in C57BL/6J mice. Behav Brain Res. 2022:418:113633.

42. Yang C, Han M, Zhang JC, Ren Q, Hashimoto K. Loss of parvalbuminimmunoreactivity in mouse brain regions after repeated intermittent administration of esketamine, but not $R$-ketamine. Psychiatry Res. 2016;239:281-3.

43. Hashimoto $\mathrm{K}$, Kakiuchi $\mathrm{T}$, Ohba $\mathrm{H}$, Nishiyama $\mathrm{S}$, Tsukada H. Reduction of dopamine $D_{2 / 3}$ receptor binding in the striatum after a single administration of esketamine, but not $R$-ketamine: a PET study in conscious monkeys. Eur Arch Psychiatry Clin Neurosci. 2017;267:173-6.

44. Tian Z, Dong C, Fujita A, Fujita Y, Hashimoto K. Expression of heat shock protein HSP-70 in the retrosplenial cortex of rat brain after administration of $(R, S)$-ketamine and (S)-ketamine, but not $(R)$-ketamine. Pharmacol Biochem Behav. 2018;172:17-21.

45. Zanos P, Moaddel R, Morris PJ, Riggs LM, Highland JN, Georgiou P, et al. Ketamine and ketamine metabolites pharmacology: Insights into therapeutic mechanisms. Pharmacol Rev. 2018;70:621-60.

46. Bonaventura J, Lam S, Carlton M, Boehm MA, Gomez JL, Solís O, et al., Pharmacological and behavioral divergence of ketamine enantiomers: implications for abuse liability. Mol. Psychiatry. 2021 Apr. https://doi.org/10.1038/s41380-02101093-2.

47. Leal GC, Bandeira ID, Correia-Melo FS, Telles M, Mello RP, Vieira F, et al. Intravenous arketamine for treatment-resistant depression: open-label pilot study. Eur Arch Psychiatry Clin Neurosci. 2021;271:577-82.

48. Duman RS, Aghajanian GK. Synaptic dysfunction in depression: potential therapeutic targets. Science. 2012;338:68-72.

49. Shirayama $Y$, Hashimoto K. Effects of a single bilateral infusion of $R$-ketamine in the rat brain regions of a learned helplessness model of depression. Eur Arch Psychiatry Clin Neurosci. 2017;267:177-82.

50. Zhang J, Ma L, Chang L, Pu Y, Qu Y, Hashimoto K. A key role of the subdiaphragmatic vagus nerve in the depression-like phenotype and abnormal composition of gut microbiota in mice after lipopolysaccharide administration. Transl Psychiatry. 2020;10:186

51. Yang C, Kobayashi S, Nakao K, Dong C, Han M, Qu Y, et al. AMPA receptor activation-independent antidepressant actions of ketamine metabolite (S)-norketamine. Biol Psychiatry. 2018;84:591-600.

52. Quadrato G, Benevento M, Alber S, Jacob C, Floriddia EM, Nguyen T, et al. Nuclear factor of activated T cells (NFATc4) is required for BDNF-dependent survival of adult-born neurons and spatial memory formation in the hippocampus. Proc Natl Acad Sci USA. 2012;109:E1499-508.

53. Fujita A, Fujita Y, Pu Y, Chang L, Hashimoto K. MPTP-induced dopaminergic neurotoxicity in mouse brain is attenuated after subsequent intranasal administration of $(R)$-ketamine: a role of TrkB signaling. Psychopharmacology. 2020;237:83-92

54. Tan Y, Fujita Y, Qu Y, Chang L, Pu Y, Wang S, et al. Phencyclidine-induced cognitive deficits in mice are ameliorated by subsequent repeated intermittent administration of $(R)$-ketamine, but not $(S)$-ketamine: Role of BDNF-TrkB signaling Pharmacol Biochem Behav. 2020;188:172839.

55. Qu Y, Shan J, Wang S, Chang L, Pu Y, Wang X, et al. Rapid-acting and long-lasting antidepressant-like actions of $(R)$-ketamine in Nrf2 knock-out mice: a role of TrkB signaling. Eur Arch Psychiatry Clin Neurosci. 2021;271:439-46.

56. Fujita $Y$, Hashimoto $Y$, Hashimoto $H$, Chang L, Hashimoto K. Dextran sulfate sodium-induced inflammation and colitis in mice are ameliorated by $(R)$-ketamine, but not (S)-ketamine: A role of TrkB signaling. Eur J Pharmacol. 2021;897:173954.

57. Zhang JC, Wu J, Fujita Y, Yao W, Ren Q, Yang C, et al. Antidepressant effects of TrkB ligands on depression-like behavior and dendritic changes in mice after inflammation. Int J Neuropsychopharmacol. 2014;18:pyu077.

58. Ma M, Ren Q, Yang C, Zhang JC, Yao W, Dong C, et al. Antidepressant effects of combination of brexpiprazole and fluoxetine on depression-like behavior and dendritic changes in mice after inflammation. Psychopharmacology. 2017;234:525-33.

59. Krämer A, Green J, Pollard J, Tugendreich S. Causal analysis approaches in Ingenuity Pathway Analysis. Bioinformatics. 2014;30:523-30.
60. Kobayashi K, Sano H, Kato S, Kuroda K, Nakamuta S, Isa T, et al. Survival of corticostriatal neurons by Rho/Rho-kinase signaling pathway. Neurosci Lett. 2016;630:45-52.

61. Zhang JC, Yao W, Qu Y, Nakamura M, Dong C, Yang $C$, et al. Increased EphA4-ephexin1 signaling in the medial prefrontal cortex plays a role in depression-like phenotype. Sci Rep. 2017;7:7133.

62. Shirayama Y, Hashimoto K. Lack of antidepressant effects of $(2 R, 6 R)$-hydroxynorketamine in a rat learned helplessness model: comparison with $(R)$-ketamine. Int J Neuropsychopharmacol. 2018;21:84-8.

63. Zhang J, Ma L, Wan X, Shan J, Qu Y, Hashimoto K. (R)-Ketamine attenuates LPSinduced endotoxin-derived delirium through inhibition of neuroinflammation. Psychopharmacology. 2021;238:2743-53.

64. Li L, Ke K, Tan X, Xu W, Shen J, Zhai T, et al. Up-regulation of NFATc4 involves in neuronal apoptosis following intracerebral hemorrhage. Cell Mol Neurobiol 2013;33:893-905.

65. Groth RD, Mermelstein PG. Brain-derived neurotrophic factor activation of NFAT (nuclear factor of activated T-cells)-dependent transcription: a role for the transcription factor NFATc4 in neurotrophin-mediated gene expression. J Neurosci. 2003:23:8125-34.

66. Rao A, Luo C, Hogan PG. Transcription factors of the NFAT family: regulation and function. Ann Rev Immunol. 1997;15:707-47.

67. Müller MR, Rao A. NFAT, immunity and cancer: a transcription factor comes of age. Nat Rev Immunol. 2010;10:645-56.

68. Zhang K, Sakamoto A, Chang L, Qu Y, Wang S, Pu Y, et al. Splenic NKG2D confers resilience versus susceptibility in mice after chronic social defeat stress: beneficial effects of $(R)$-ketamine. Eur Arch Psychiatry Clin Neurosci. 2021:271:447-56.

69. Burcusa SL, lacono WG. Risk for recurrence in depression. Clin Psychol Rev. 2007;27:959-85.

\section{ACKNOWLEDGEMENTS}

We thank The Stanley Medical Research Institution (MD, USA) for providing the postmortem tissue samples from psychiatric disorders. LM was supported by the Uehara Memorial Foundation (Tokyo, Japan). This study was supported by Japan Agency for Medical Research and Development (to KH, JP20dm0107119), Japan Society for the Promotion of Science (to KH 21H02846), SENSHIN Medical Research Foundation (to $\mathrm{KH}$ ), Perception Neuroscience (to $\mathrm{KH}$ ), and National Natural Science Foundation of China (to LW, 81772044).

\section{AUTHOR CONTRIBUTIONS}

$\mathrm{KH}$ designed the experiment. LM, JZ, YF, YQ, JS, XW, XW, and TI performed the experiments. KK prepared AAV. LM, and LW performed an analysis of RNA-seq data. $\mathrm{LM}$ and $\mathrm{KH}$ wrote the manuscript. All authors read and approved the manuscript.

\section{COMPETING INTERESTS}

$\mathrm{KH}$ is the inventor of filed patent applications on "The use of $R$-Ketamine in the treatment of psychiatric diseases", "(S)-norketamine and salt thereof as pharmaceutical", "R-Ketamine and derivative thereof as prophylactic or therapeutic agent for neurodegeneration disease or recognition function disorder", "Preventive or therapeutic agent and pharmaceutical composition for inflammatory diseases or bone diseases", and "R-Ketamine and its derivatives as a preventive or therapeutic agent for a neurodevelopmental disorder" by the Chiba University. KH has also received speakers' honoraria, consultant fee, or research support from Abbott, Meiji Seika Pharma, Dainippon-Sumitomo, Taisho, Otsuka, Murakami Farm, and Perception Neuroscience. Other authors declare no conflict of interest.

\section{ADDITIONAL INFORMATION}

Supplementary information The online version contains supplementary material available at https://doi.org/10.1038/s41398-022-01803-6.

Correspondence and requests for materials should be addressed to Kenji Hashimoto.

Reprints and permission information is available at http://www.nature.com/reprints

Publisher's note Springer Nature remains neutral with regard to jurisdictional claims in published maps and institutional affiliations. 
(c) (i) Open Access This article is licensed under a Creative Commons Attribution 4.0 International License, which permits use, sharing, adaptation, distribution and reproduction in any medium or format, as long as you give appropriate credit to the original author(s) and the source, provide a link to the Creative Commons license, and indicate if changes were made. The images or other third party material in this article are included in the article's Creative Commons license, unless indicated otherwise in a credit line to the material. If material is not included in the article's Creative Commons license and your intended use is not permitted by statutory regulation or exceeds the permitted use, you will need to obtain permission directly from the copyright holder. To view a copy of this license, visit http://creativecommons. org/licenses/by/4.0/.

(c) The Author(s) 2022 